\title{
Fertility behaviour in Uganda: Does partner age difference matter?
}

\author{
Emmanuel O. Olamijuwon ${ }^{1}$ and Jeremy Gumbo ${ }^{2}$ \\ 1Department of Demography and Population Studies Programme, \\ University of the Witwatersrand, Johannesburg, South Africa. \\ juwohn@gmail.com \\ ${ }^{2}$ Chris Hani Baragwanath Hospital, \\ Soweto, Johannesburg, South Africa.
}

\begin{abstract}
High fertility in developing countries often strains socio-economic resources and impedes the achievements of national policies and individual goals. In this study, we investigated the effect of partner age difference on fertility in Uganda, a high fertility country in Sub-Sahara Africa. Data was drawn from the 20ll Uganda Demographic and Health Survey. Poisson regression model was used to isolate the effect partner age difference on fertility. Our findings from both unadjusted and adjusted regression models suggested that partner age difference had no effect on fertility in Uganda. However, the observed direction of flow was that; women with younger partners had slightly lower fertility (IRR:0.97 $\mathrm{Cl}$ 0.8446-I.I 159) while those with older partners by I-5years had slightly higher fertility (IRR:I.05 $\mathrm{Cl}: 0.9532-1.1652$ ) relative to women whose age was not different from their partners'.
\end{abstract}

Keywords: age difference, fertility, Uganda, partners, DHS.

\section{Introduction}

High fertility in less developed countries like Uganda is a major challenge for planners because a rapidly growing population in reduces adequate investments in education, healthcare services, jobs creation, and other basic essentials that boost standards of living (Ashraf, Weil, and Wilde, 20/3). Research has observed that high fertility is an impediment to the achievement of both national and individual goals because it exerts pressure on resources (Rabiu and Ahmad, 20l4). High fertility can also lead to poor health outcomes for both the mother and the child, pose environmental threats and hinder opportunities for economic development (Ashraf, Weil, and Wilde, 2013; Kravdal et al., 2012; World Bank, 20I0; Alter, Dribe and Van Poppel, 2007).

Uganda ranks among high fertility countries in the world with a total fertility rate (TFR) of 6.2 (Asiki et al., 2016; UBOS, 2014). Its population growth rate of about $3.2 \%$ ranks sixth among countries with the highest population growth rate in the World and is expected to increase to about 46.7 million by the year 2025, an increase of 11.8 million persons in I lyears (Asiki et al., 2016; UBOS., 20I4).

The country's high fertility has resulted in a very young population of those aged 15 years accounting for about $52 \%$ of the total population (Musisi, 2015; POPSEC, 2014). This is further reflected by the country's high dependency ratio of; 103 dependents http://aps.journals.ac,za for every 100 working persons, the second-highest in the world after Niger (Hausmann et al., 2014, World Bank, 2013). High fertility should partly explain the country's poor record on health care service provision. (Levin et al, 2003). Excessive increase in demand for health care services for infants has exposed the country's inability to cope with up with the escalating population, resulting in infant mortality rate of 54 for every I,000 live births (Republic of Uganda, 20l4).

Increasing numbers of sexually active youths partly account for high fertility in Uganda (Bbaale and Mpuga, 200I). About a quarter of girls aged 15-19 years in Uganda are pregnant or are already mothers (UBOS and ICF International Inc., 20I I). Policies and laws on child marriage are not adequately enforced in Uganda, and as a result, about $49 \%$ of Ugandan girls are married off before they age 18 years. (Gammage et al., 20।6; UNFPA 20I3).

Achieving fertility reduction is said to be dependent upon the action of individuals or couples to reduce the number of children ever born (Bongaarts, 2003). However, efforts in controlling fertility in Uganda through program and commercial campaign strategies are yet to yield plausible results (Katende, Gupta, and Bessinger, 2003). Despite Uganda's family planning policy, contraceptive use is still very low in the country, one of the lowest in the 
world (MOH, 2006; UBOS, 2007). Similarly, in most African settings especially among couples, men are likely to be significantly older than their wives in terms of age difference, and it is rare to identify a family where the reverse is the case (Adebowale and Palamuleni, 20I4). Conversely, in some districts of the country, women are likely to have had their first sex with older partners which are perceived to be associated with less likelihood of contraceptive use (Tumwesigye, Ingham, and Holmes, 2013).

High human fertility is known to be resulting from a number of factors, and several studies have tried to examine the socio-economic factors associated with high fertility in Uganda (Buyinza and Hisali, 20l4; Vavrus and Ulla, 2003; Westoff and Bankole, 2002; Bbaale and Mpuga, 200I). Studies on partner age difference as well had only focused on its association with spousal violence and HIV/AIDS transmission neglecting its contribution to fertility (Buyinza and Hisali, 20I4; Vavrus and Ulla, 2003). Rarely has researchers explored the relationship between partner age difference and fertility.

A proper understanding of this relationship will therefore be of necessity in achieving a substantial fertility reduction in the country. An awareness of this relationship will also help in achieving the country's 2008 population policy and also its action plan of 20II which is aimed at addressing the issues of appropriate planning for a rapidly growing population. It will also contribute to the body of knowledge on fertility determinants and the mechanisms underlying fertility decision among couples in Uganda.

\section{Literature Review and Theoretical Framework Partner Age Difference and Fertility}

Partner age difference has been shown in previous studies as one of the key factors influencing household decisions including fertility and contraceptive use (Laguna et al., 2000). Partner endorsement of family planning is also decisive in the patterns of age difference between partners (Gebreselassie and Mishra, 2007; Manlove et al., 2003). A number of studies have reported that the use of contraception by women is associated with the level of communication with their partners and this may, in turn, explain why age difference between partners appears also to influence fertility (AmoAdjei, 20 I2; Manlove et al., 2004; Kaestle et al., 2002; Crosby et al., 2002; Stone and Ingham, 2002; Gregson et al., 2002). Manlove et al. (2003) also found that adolescents with older sexual partners were significantly less likely to consistently use contraception which is why these young women are substantially at risk of high fertility and HIV infections compared to women with no partner age difference (Manlove et al., 2003).

More recently, studies have also shown that the use of modern contraceptives and sex refusal were likely to fall consistently with increasing partner age difference and ultimately important factors for fertility control (Adebowale and Palamuleni, 2014; Mohammad, 2013). A similar pattern of fertility of was found among women in Orissa, an eastern Indian state where lower partner age difference showed a significant decline in fertility (Nanda, 2005).

\section{Other Predictors of Fertility}

Education has also been widely held to be a key determinant of fertility, and it is perceived that as the overall education level rises, social norms concerning childbearing and parenting change and couples choose to have fewer children (Rabiu and Ahmad, 20I4).

For instance, a comparative analysis of fertility differentials in Ghana and Nigeria observed that there is an association between level of educational attainment and the total fertility rates (Olatoregun et al., 20l4). Their study found that women with primary education were more likely to have higher fertility compared to those with higher education in both countries (Olatoregun et al., 20I4). Similarly, a study of the effects of average length of a woman's education on fertility in Peru concluded that women who spend a long time schooling are likely to have fewer children than those who spend less or no time at all (Barber et al., 2002). This is obviously because the woman would have spent an extended period of her childbearing years in school, thus shortening the years of risk of pregnancies (Barber et al., 2002).

More also, a study of fertility differentials in Osun State, Nigeria found that there was a significant difference in the fertility levels of adolescents and older mothers (Oyefara, 20I2). Specifically, adolescent mothers in the study had a relatively higher fertility compared to older mothers (Oyefara, 20I2).

Uddin et al. (20I I) have also noted that women from rural areas had both higher fertility and desired family size than those from the urban areas. Their findings are also consistent with another study in Nigeria where women living in urban areas had fewer children compared to their rural counterparts (Oyefara, 20I2; Rabiu and Ahmad, 20I4). Suggestions are that women in urban areas tend to have more education and are more likely to participate in the formal labour market (Oyefara, 20I2). These women are likely to appreciate the advantage of having a smaller family, and also have better knowledge of and access to modern contraception than women in the rural areas (Oyefara, 2012; Cernic and Kveder, 2008; 
Boyle, 2003). Research has further observed that spousal agreement on the use of family planning tends to be higher in urban areas relative to rural areas (Gebreselassie and Mishra, 2007).

Researchers have also noted that household wealth status has an effect on fertility as fertility is likely to higher among the individuals who are poor compared to those who are rich (Adhikari, 20I0). This may be due perceived benefits of having more children, as well as less access to contraceptive methods among poor individuals (Adhikari, 20I0). The researcher also noted place of residence, literacy status, sex of household head and an experience of the death of own's child as other significant factors of high fertility.

Uddin et al. (20l I) observed that an increase in child mortality also increases a woman's fertility behaviour in Bangladesh (Uddin et al., 20II). Their study also confirmed that those who had experienced child mortality have higher parity level compared to their expectation of offspring (Uddin et al., 20 I I).

Indications are that previous studies have largely ignored the effect that age differences in relationships may have on fertility in Uganda. As indicated above, a substantial number of females in the country become mothers at tender ages. In a country where child marriages are highly tolerated, these young women are likely to have sexual partners who are very old. In this study, we argue that partner age differences partly accounts for high fertility in Uganda. For, young females may not be able to negotiate contraceptive use as well as their desired family size in face of their older partners who due to traditional beliefs may desire more children. We hypothesize that women who have higher partner age difference have higher fertility compared to women with same partner age difference.

\section{Data and Methods}

This cross-sectional study uses secondary data from the 20II Uganda Demographic and Health Survey (UDHS). The survey is a nationally representative sample of the country's entire population residing in non-institutional dwelling units (UDHS, 20II). The population of interest for this study are women in union aged 40-49 who have had fertility experience. We also exclude women with no fertility experience since they are not relevant to our investigation. Sample for this study is, therefore, a weighted distribution of 884 women.

\section{Outcome Variable}

The outcome variable for this research is fertility which was measured using the completed total number of children ever had by a woman. Responses were measured as counts from I to 9 .

\section{Predictor Variables}

Main predictor variable is partner age difference which was derived by subtracting a woman's current age from the partner's age to measure the age difference. Resultant categories were classified as; I implying 'younger partner', 2 'no age difference', 3 'older partner by $1-5$ years', 4 'older partner by 6-10 years' and 5 'older partner by $1 /$ or more years'. Other predictors that were included in the study as control variables are women's educational attainment, place of residence, religious affiliation, partner education, household wealth status, child mortality experience and age at first birth all of which were guided by reviewing of relevant literature. Women's educational attainment as was categorized as ' 0 ' for women with no formal education, ' $I$ ' for women with primary education, ' 2 ' for women with secondary education, and ' 3 ' for women with higher education. The plce of residence was coded as ' 0 ' for women residing in urban residence and ' $\mathrm{l}$ ' for women living in the rural place of residence. Religious affiliation was classified as ' $0=$ Christian' for women who reported being Catholic, Protestant, Pentecostal and SDA, 'I=Muslim' for women reported being Muslims and ' $2=$ Others' for women in other religious groups. Partner educational attainment was coded; ' 0 ' implying no education, ' $l$ ' primary education, ' 2 ' secondary education and ' 3 ' higher education. Household wealth status was categorised as; Poor for individuals reported as poorer and poorest; Medium; and Rich for individuals reported as richer and richest.

\section{Analytical Approach}

Frequencies and charts were used to explore the levels of fertility in Uganda and also describe the study population. A stepwise Poisson regression (PR) was used to model the association between partner age difference and fertility, controlling other associated factors outlined above. The PR was opted for because the outcome variable is count and nonnegative integer. Tests for over-dispersion of the outcome variable as well as goodness showed that the model fits the data well. Data management and all analysis were conducted using Stata version 13 software. Weighting of responses was done to correct for sampling error and to ensure that the sample is a true representation of the entire population. Interpretation of results was done using incidence rate ratios (IRR) with the level of significance set at $\mathrm{p}<0.05$ and confidence intervals of 95\%. An IRR =I; IRR $>I$; and IRR $<$ I means that there's no difference in the expected number of births, higher expected number of births and lower expected number of births across the respective characteristics. 
Model equation: $\mu_{i}=\exp \left(a+\beta^{i} X^{i i}+\beta^{2} X^{2 i}+\right.$ $\left.\beta^{3} X^{3 i} \ldots . .+\beta^{k} X^{k i}\right)$

where $\mu_{i}$ is the completed number of children ever born for $i^{\text {th }}$ woman; $X^{1 i}, X^{2 i}, X^{3 i} \ldots X^{k i}$ are the woman, her partner and household characteristics; and $a, \beta^{i}, \beta^{2}, \beta^{3} \ldots \beta^{k}$ are the regression coefficients (Poston and McKibben, 2003).

\section{RESULTS}

\section{Descriptive Profile of Women}

The mean age at first birth in Uganda was 19 years and an average of 8 -live births per woman. Findings in Table I shows that majority (about $85 \%$ ) of the women are younger than their partner while about $9 \%$ are older than their partner. A large percentage of the women also reside in the rural place of residence $(89 \%)$, and the majority are reported to be Christians. More than two-third of the women have some formal education, and about $42 \%$ are reported to be rich. About two-thirds have also experienced at least a child death. Examining the levels of fertility by partner age difference as presented in Figure I, we observed that the mean completed fertility increases as age difference increases except women who have a partner older by $\mathrm{I}-5$ years.

Association between Partner Age Difference and Fertility Controlling for other Socio-Demographic Characteristics

Table 2 below shows the unadjusted and adjusted effects of partner age difference on fertility. For the former, findings were that women with a younger partner had lower fertility (IRR: 0.94; and Cl: 0.82I.09) when compared to women with no age difference. Similarly, those with an older partner by I-5 years had higher fertility (IRR: I.05; Cl: $0.94-$ I.16) and those with older partner by more than 10 years also had higher fertility (IRR: I.03 Cl: $0.92-$ I.I6) when compared to those with no age difference although no statistically significant association could be observed while also controlling for other important predictors. Findings from the latter (adjusted) did not suggest any difference. Control variables that had significant influences on fertility as shown in Table 2 were place of residence, educational attainment, age at first birth and child mortality experience. For instance, women with secondary had (IRR: 0.86; with $\mathrm{Cl}: 0.78-0.95$ ) and those with higher education (IRR: $0.8 \mathrm{I} \mathrm{Cl:} 0.68-$ $0.95)$ have lower fertility compared to women with no formal education. Women in the rural residence (IRR: I.I5 Cl: 1.07 - I.25) also have a significantly higher fertility compared to their counterparts in the urban place of residence. Women who have experienced at least a child mortality (IRR: I.20 Cl: I.I4 - I.27) were also significantly likely to have a higher fertility compared to those who had not lost any child. A year increase in age at first birth also reduces fertility by $2 \%$ and the relationship is also significant while adjusting for other variables in the model.

Figure I: Mean Completed Fertility by Partner Age Difference

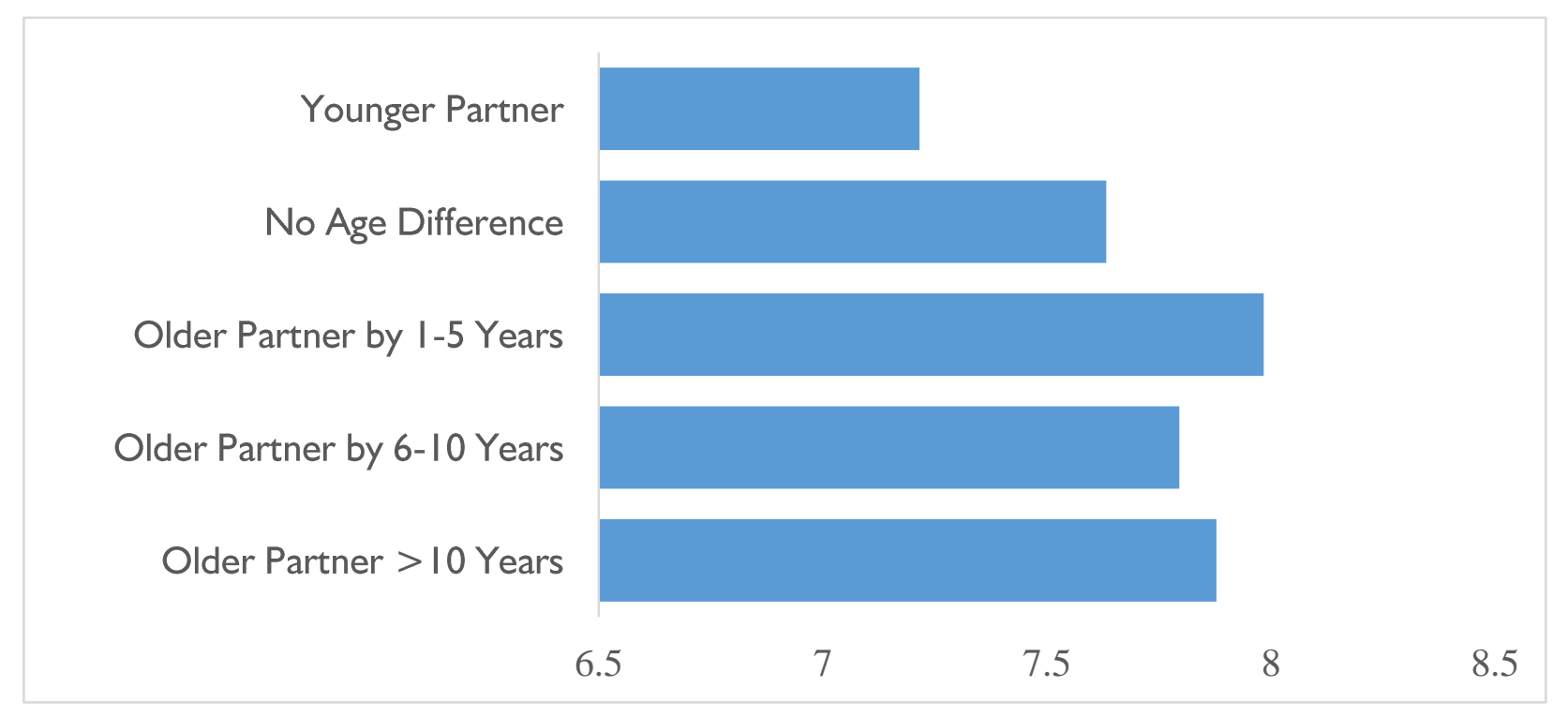




\begin{tabular}{|c|c|}
\hline Background Variables & Percentage $(n=885)$ \\
\hline \multicolumn{2}{|l|}{ Fertility } \\
\hline Mean Fertility & 8 \\
\hline \multicolumn{2}{|l|}{ Partner Age Difference } \\
\hline Younger Partner & 9.2 \\
\hline No Age Difference & 5.4 \\
\hline Older Partner by I- 5 Years & 37.2 \\
\hline Older Partner by 6-10 Years & 27.6 \\
\hline Older Partner $>10$ Years & 20.7 \\
\hline \multicolumn{2}{|l|}{ Women's Educational Attainment } \\
\hline No Education & 31.0 \\
\hline Primary & 56.6 \\
\hline Secondary & 9.6 \\
\hline Higher & 2.8 \\
\hline \multicolumn{2}{|l|}{ Place of Residence } \\
\hline Urban & 11.2 \\
\hline Rural & 88.8 \\
\hline \multicolumn{2}{|l|}{ Women's Religious Affiliation } \\
\hline Christian & 86.3 \\
\hline Muslim & 12.8 \\
\hline Others & 0.9 \\
\hline \multicolumn{2}{|l|}{ Partner Educational Attainment } \\
\hline No Education & 12.1 \\
\hline Primary & 60.4 \\
\hline Secondary & 19.0 \\
\hline Higher & 8.5 \\
\hline \multicolumn{2}{|l|}{ Household Wealth Status } \\
\hline Poor & 37.6 \\
\hline Middle & 20.4 \\
\hline Rich & 42.0 \\
\hline \multicolumn{2}{|l|}{ Child Mortality Experience } \\
\hline No & 33.4 \\
\hline Yes & 66.6 \\
\hline \multicolumn{2}{|l|}{ Age at First Birth } \\
\hline Mean (Years) & 19.0 \\
\hline
\end{tabular}


Table 2: Multivariate Poisson Regression Model

\begin{tabular}{|c|c|c|}
\hline Background Variables & Crude IRR (Cl) & Adjusted IRR (Cl) \\
\hline \multicolumn{3}{|l|}{ Partner Age Difference } \\
\hline Younger Partner & $0.94(0.82-1.09) \neq \ddagger$ & $0.97(0.84-1.11) \neq \ddagger$ \\
\hline No Age Difference & Ref & Ref \\
\hline Older Partner by I-5 Years & $1.05(0.94-1.16) \neq \ddagger$ & $1.05(0.95-1.17)$ 㧊 \\
\hline Older Partner by 6-10 Years & $1.02(0.91-1.14) \neq \neq$ & $1.00(0.90-1.11) \neq \ddagger$ \\
\hline Older Partner > 10 Years & $1.03(0.92-1.16) \neq \neq$ & $1.04(0.93-1.15) \neq \ddagger$ \\
\hline \multicolumn{3}{|l|}{ Educational Attainment } \\
\hline No Formal Education & Ref & Ref \\
\hline Primary & $0.98(0.93-1.04) \neq \neq$ & $1.01(0.95-1.07) \neq \ddagger$ \\
\hline Secondary & $0.77(0.70-0.84) * *$ & $0.86(0.78-0.95) * *$ \\
\hline Higher & $0.64(0.53-0.78) * *$ & $0.8 \mathrm{I}(0.68-0.96) * *$ \\
\hline \multicolumn{3}{|l|}{ Place of Residence } \\
\hline Urban & Ref & Ref \\
\hline Rural & $1.32(1.23-1.42) * *$ & $1.15(1.07-1.25) * *$ \\
\hline \multicolumn{3}{|l|}{ Religious Affiliation } \\
\hline Christian & Ref & Ref \\
\hline Muslim & $1.01(0.93-1.09) \neq \ddagger$ & $1.05(0.97-1.13) \neq \ddagger$ \\
\hline Others & $0.90(0.82-1.17)$ 㧊 & $0.90(0.78-1.05) \neq \ddagger$ \\
\hline \multicolumn{3}{|l|}{ Partner Educational Attainment } \\
\hline No Formal Education & $1.15(1.02-1.30) * *$ & $0.94(0.83-1.06) \neq \ddagger$ \\
\hline Primary & $1.22(1.1 \mid-1.36) * *$ & $1.01(0.9202-1.11) \neq \neq$ \\
\hline Secondary & $1.15(1.02-1.29) * *$ & $1.02(0.93-1.12) \neq \ddagger$ \\
\hline Higher & $\operatorname{Ref}$ & Ref \\
\hline \multicolumn{3}{|l|}{ Household Wealth Status } \\
\hline Poor & $1.11(1.05-1.18)$ *** & $0.94(0.89-1.01) \neq \ddagger$ \\
\hline Average & $1.16(1.09-1.25)^{* *}$ & $0.92(0.86-0.99) * *$ \\
\hline Rich & Ref & Ref \\
\hline \multicolumn{3}{|l|}{ Child Mortality } \\
\hline No & Ref & Ref \\
\hline Yes & $1.27(1.20-1.35) * *$ & $1.20(1.14-1.27)^{* *}$ \\
\hline Age at First Birth & $0.98(0.97-0.99) * *$ & $0.98(0.98-0.98) * *$ \\
\hline
\end{tabular}

¥¥ - Not Significant p $\geq 0.05$; ** - Significant at $p<0.05$; Ref- Reference Category

\section{Discussion of Findings}

The objective of this study was to determine whether partner age difference has an effect on fertility in Uganda. This investigation was largely motivated by prior findings which have suggested that women who are older than their partner are more likely to have more contribution in household decision making especially those that have to do with contraceptive use than women who are younger than their partner (Amo-Adjei, 20I2; Nanda, 2005).

Our findings could however not confirm our hypothesis since the association of interest in this study proved to be none significant. Our findings were therefore unable to confirm findings from prior studies which had indicated that fertility increased, as partner age gap widens (Amo-Adjei, 20I2; Nanda,
2005). Such findings were not expected in a country like Uganda where male dominance is tolerated (Manlove, Ryan, and Franzetta, 2003). However, the direction of flow was very much coherent with what had come from prior studies as women with wide age differences with partners had slightly higher fertility relative to those with less partner age difference.

As for control variables findings were that women with secondary and higher education had lower fertility is supported by another study of fertility differentials in Nigeria and Ghana (Olatoregun et al., 2014). This may be because educated women are often empowered and exposed to information that makes them more likely to be employed outside their 
home environment thereby giving them more awareness regarding their health and that of their children (Olatoregun et al., 2014; Adhikari, 2010). Education is also perceived to enable women choose smaller family size, postpone marriage and also use contraception (Adhikari, 20 I0). Our finding that place of residence is a significant predictor of fertility in Uganda may also be because fertility is perceived to be linked to economic and social characteristics of life settings and is connected with structural and cultural characteristics of the social environment (Rabiu and Ahmad, 20I4; Ushie et al., 20I I; Cernic and Kveder, 2008). For instance, women in the urban residence tend to have more education and are more likely to participate in the formal labour market coupled with a higher tendency to appreciate a smaller family, have better knowledge and access to modern contraception than women in the rural areas (Oyefara, 20I2). Similarly, this study found child mortality to have a significant association with fertility and this is consistent with another study of fertility differentials in Bangladesh (Uddin et al., 20II). This observed relationship is perceived to be because child mortality plays a vital role in expecting and obtaining offspring and women with some child mortality experience tend are likely to desire more children in other to compensate for the dead ones (Uddin et al., 20l I). In the same manner, a woman's age at first birth was also found in this study to influence fertility and this may be because early onset of childbearing increases a woman's risk and exposure to fertility compared to a late age at first birth (Oyefara, 20I2).

\section{Conclusion and Recommendations}

This study indicated that a partner age difference does not really matter in explaining fertility in Uganda. Therefore strategizing against having young women not to be in union with older partners may not necessarily contribute to significant reductions in fertility among in Uganda. Rather, there are other characteristics like place of residence which proved to be significant in explaining high fertility in this country. We however encourage further research on this association to authenticate our findings since our investigation was cross sectional which may have been affected by temporal limitations of the data.

\section{Acknowledgement}

We acknowledge ICF International for granting us permission to use the Uganda Demographic and Health Survey dataset for this study. Staff and students of the Demography and Population Studies programme, University of the Witwatersrand, Johannesburg, South Africa for their support.

\section{References}

Adebowale, A. and Palamuleni, M. 2014. "Modern Contraceptive Use, Sex Refusal and Spousal Difference in Level of Education among Married Women in Nigeria: Are They Interrelated?" International Journal of Humanities and Social Science 4(6): 217-230.

Adhikari, R. 2010. "Demographic, socio-economic, and cultural factors affecting fertility differentials in Nepal." BMC Pregnancy and Childbirth I0(19): III.

Alter, G., Dribe, M. and Van Poppel, F. 2007. "Widowhood, family size, and post-reproductive mortality: a comparative analysis of three populations in nineteenth-century Europe." Demography 44(4): 785-806.

Amo-Adjei, J. 2012. "Age differences and protected first heterosexual intercourse in Ghana." African Journal of Reproductive Health 16(4): 58-67.

Ashraf, Q. H., Weil, D. N. and Wilde, J. 2013. "The effect of fertility reduction on economic growth." Population and development review, 39(I): 97I30.

Asiki, G., Newton, R., Marions, L., Seeley, J., Kamali, A., and Smedman, L. 2016. "The impact of maternal factors on mortality rates among children under the age of five years in a rural Ugandan population between 2002 and 2012." Acta Paediatrica 105(2): 191-199.

Barber, J.S., Pearce, L.D., Chaudhury, I., Gurung, S. 2002. "Voluntary Associations and Fertility Limitation." Social Forces 80(4): | 369-| 40 I.

Bbaale, E. and Mpuga, P., 200I. "Female Education, Contraceptive Use, and Fertility: Evidence from Uganda." Consilience: The Journal of Sustainable Development 6(I): 20-47.

Bongaarts, J. 1978. "A framework for analyzing the proximate determinants of fertility." Population and development review 4(I): 105-1 32.

Bongaarts, J. 2003. "Completing the fertility transition in the developing world: The role of educational differences and fertility preferences." Population Studies 57(3): 321-335.

Boyle, P. 2003. "Population Geography: does geography matter in fertility research?" Progress in Human Geography 27: 615-626.

Buyinza, F. and Hisali, E. 2014. "Microeffects of Women's Education on Contraceptive Use and Fertility: The Case of Uganda." Journal of International Development 26(6): 763-778.

Cernic, I. M. and Kveder, A. 2008. "Declining Fertility on the Frontier: The Ecuadorian Amazon." Population and Environment 28(I): 17-39.

Crosby, R. et al., 2002. "Condom use and correlates of African American adolescent females' infrequent communication with sex partners 
about preventing sexually transmitted diseases and pregnancy." Health Education \& Behaviour 29(2): 2|9-23|.

Gammage, S., Kabeer, N., and van der Meulen Rodgers, Y. 2016. "Voice and agency: where are we now?" Feminist Economics 22(I): I-29.

Gebreselassie, T. and Vinod M. 2007. "Spousal agreement on family planning in sub-Saharan Africa." DHS Analytical Studies No. II. Calverton, Maryland, USA: Macro International. Available at http://dhsprogram.com/pubs/pdf/ASI I/ASI I.pdf.

Gregson, S. et al., 2002. "Sexual mixing patterns and sex differentials in teenage exposure to HIV infection in rural Zimbabwe." Lancet 359(9321): I896-1903.

Hausmann, R., Matovu, J., Osire, R. and Wyett, K. 2014. "How Should Uganda Grow?" ESID Working Paper No. 30, Effective States and Inclusive Development Research Centre (ESID), Manchester, U.K.

Kaestle, C. E., Morisky, D. E. and Wiley, D. J. 2002. "Sexual intercourse and the age difference between adolescent females and their romantic partners." Perspectives on Sexual and Reproductive Health 34: 304-309.

Katende, C., Gupta, N. and Bessinger, R. 2003. "Facility-level reproductive health." International Family Planning Perspectives 29(3): I30-I 37.

Kravdal, O., Grundy, E., Lyngstad, T. and Wiik, K. 2012. "Family life history and late mid-life mortality in Norway." Population and development review 38(2): 237-257.

Laguna, E.P., Po, A.L., Perez, A.E., and Kanter, A. 2000. "Contraceptive use dynamics in the Philippines: determinants of contraceptive method choice and discontinuation." Population Institute, University of the Philippines.

Levin, A., Dmytraczenko, T., McEuen, M., Ssengooba, F., Mangani, R. and Van Dyck, G. 2003. "Costs of maternal healthcare services in three Anglophone African countries." International Journal of Health Planning Management, 18: 3-22.

Long, J.S. 1997. "Regression models for categorical and limited dependent variables." Thousand Oaks, California: Sage Publications.

Manlove, J., Ryan, S. and Franzetta, K. 2003. "Patterns of contraceptive use within teenagers' first sexual relationships." Perspectives on Sexual and Reproductive Health 35(6): 246-255.

Manlove, J., Ryan, S. and Franzetta, K. 2004. "Contraceptive use and consistency in U.S. Teenagers' most recent sexual relationships." Perspectives on Sexual and Reproductive Health 36(6): 265-275.
Manlove, J., Ryan, S., and Franzetta, K. 2003. "Patterns of Contraceptive Use Within Teenagers' First Sexual Relationships." Perspectives on Sexual and Reproductive Health 35(6): 246-255.

Mohammad, A. I. 2013. "Influence of Spousal Age Difference on Fertility: A Study on Married Adolescent Girls in Bangladesh." A paper presented at Population Association of America meeting in 2013.

Musisi, S. 2015. "Caring for the Elderly with Dementia in Africa." In Brain Degeneration and Dementia in Sub-Saharan Africa 287-297. Springer New York.

Nanda, S. 2005. "Cultural Determinants of Human Fertility: A Study of Tribal Population in Orissa." Anthropologist 7(3): 22I-227.

Olatoregun, O. et al. 20I4. "A Comparative Analysis of Fertility Differentials in Ghana and Nigeria." African Journal of Reproductive Health I8(3): 3647.

Oyefara, J. 2012. "Age at first birth and fertility differentials among women in Osun State, Nigeria." European Scientific Journal 8(16).

Population Secretariat (2014). The State of Uganda Population Report 2014. Kampala: Ministry of Finance, Planning, and Economic Development. Retrieved from http://popsec.org/wpcontent/uploads/20 I/I I/STATE-OFUGANDAPOPULATION-REPORT-2014.pdf

Poston Jr, D. L., and McKibben, S. L. 2003. "Using zero-inflated count regression models to estimate the fertility of US women." Journal of Modern Applied Statistical Methods 2(2): 10.

Rabiu, S. and Ahmad, M. 2014. "Education, Place of Residence and Fertility Differentials Among Women in Nigeria." International Journal of Social Sciences and Humanities Review 4(4): 79-83.

Stone, N. and Ingham, R., 2002. "Factors affecting British teenagers' contraceptive use at first intercourse: the importance of partner communication." Perspectives on Sexual and Reproductive Health 34: 191-197.

Tumwesigye, N. M., Ingham, R., and Holmes, D. 2013. "Condom use at first and latest sexual events among young people: evidence from a rural and peri-urban setting in Uganda." African health sciences I3(2): 407-4I4.

UBOS and ICF International Inc, 2012. "Uganda Demographic and Health Survey 20I I." Kampala: Uganda Bureau of Statistics.

UNFPA, 2013. Motherhood in childhood: Facing the challenge of adolescent pregnancy., Kampala: State of World Population Report.

Ushie, M., Ogaboh, A., Olumodeji, E. and Attah, F. 2011. "Socio-cultural and economic determinants of fertility differentials in rural and urban Cross 
Rivers State, Nigeria." Journal of Geography and Regional Planning 4(7): 383.

Vavrus, F. and Ulla, L. 2003. "Girls' education and fertility transition: An analysis of recent Trends."
Economic Development and Cultural Change 5I (4): 945-976. 